\title{
Eficiência Energética em Equipamentos de Força Motriz
}

\section{Introdução}

A produção de energia mecânica, através da utilização de motores eléctricos, absorve cerca de metade da energia eléctrica consumida no nosso País, da qual apenas metade é energia útil. Este sector é, pois, um daqueles em que é preciso tentar fazer economias, prioritariamente. O êxito neste domínio depende, em primeiro lugar, da melhor adequação da potência do motor à da máquina que ele acciona. Quando o regime de funcionamento é muito variável para permitir este ajustamento, pode-se equipar o motor com um conversor electrónico de variação de velocidade. Outra possibilidade é a utilização dos motores "de perdas reduzidas" ou de "alto rendimento", que permitem economias consideráveis.
Também a nível Europeu, os motores eléctricos representam uma das fontes mais consumidoras de energia: $70 \%$ do consumo eléctrico na indústria e cerca de $1 / 3$ do consumo eléctrico no sector dos serviços.

Nos últimos anos, muitos fabricantes de motores investiram fortemente na pesquisa e desenvolvimento de novos produtos com o objectivo de colocarem no mercado motore mais eficientes.

\section{Eficiência dos Motores}

Os motores eléctricos convertem a energia eléctrica em energia mecânica. No entanto o rendimento desta conversão não é de $100 \%$. A energia eléctrica é convertida em energia

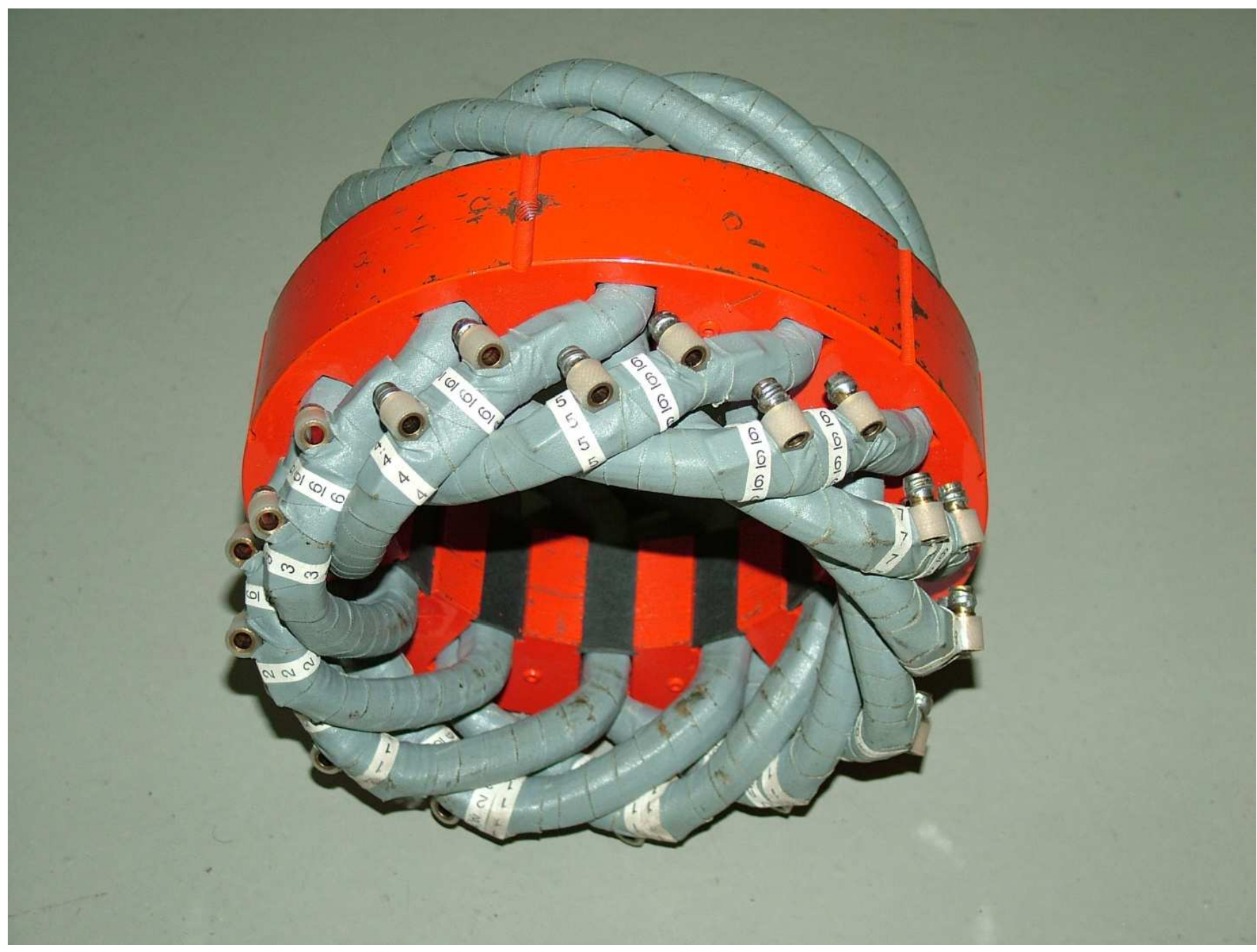




\section{ARTIGO TÉCNICO}

mecânica e em perdas. Estas perdas são devidas aos dive elementos que estão presentes na conversão e podem divididas em quatro tipos:

- Perdas eléctricas;

- Perdas magnéticas;

- Perdas mecânicas;

- Perdas parasitas.

As perdas eléctricas são provocadas pela resistência não dos condutores das bobines que ao serem percorridos corrente provocam perdas caloríficas. As perdas magnét ocorrem nas lâminas de ferro do estator e do rotor deviı histerese e às correntes de Foucault. As perdas mecâr são provocadas pela rotação das peças móveis, ventilaçi atrito do ar. As perdas parasitas são devidas a fugi irregularidades de fluxo e, também, distribuição de corrı não uniforme.

Para se quantificar o valor do rendimento de um mot necessário conhecer certos parâmetros, tais como as pe e a potência mecânica disponibilizada para a carga. Taml é necessário conhecer algumas características da máquina para que se possa fazer a sua modelização e simulação em vários regimes de carga. Os testes e estudos a efectuar para se determinar o rendimento de um motor de indução são descritos na norma CEI 34-2.

A eficiência de um motor é dada pelo seu rendimento, ou seja, pela relação entre a quantidade de energia eléctrica que absorve e a quantidade de energia mecânica que produz e pode ser calculada pela expressão seguinte.

$$
\eta=\frac{\text { Pmec }}{\text { Pabs }}(\%)=\frac{\text { Pmec }}{\text { Pmec }+ \text { Pperdas }}
$$

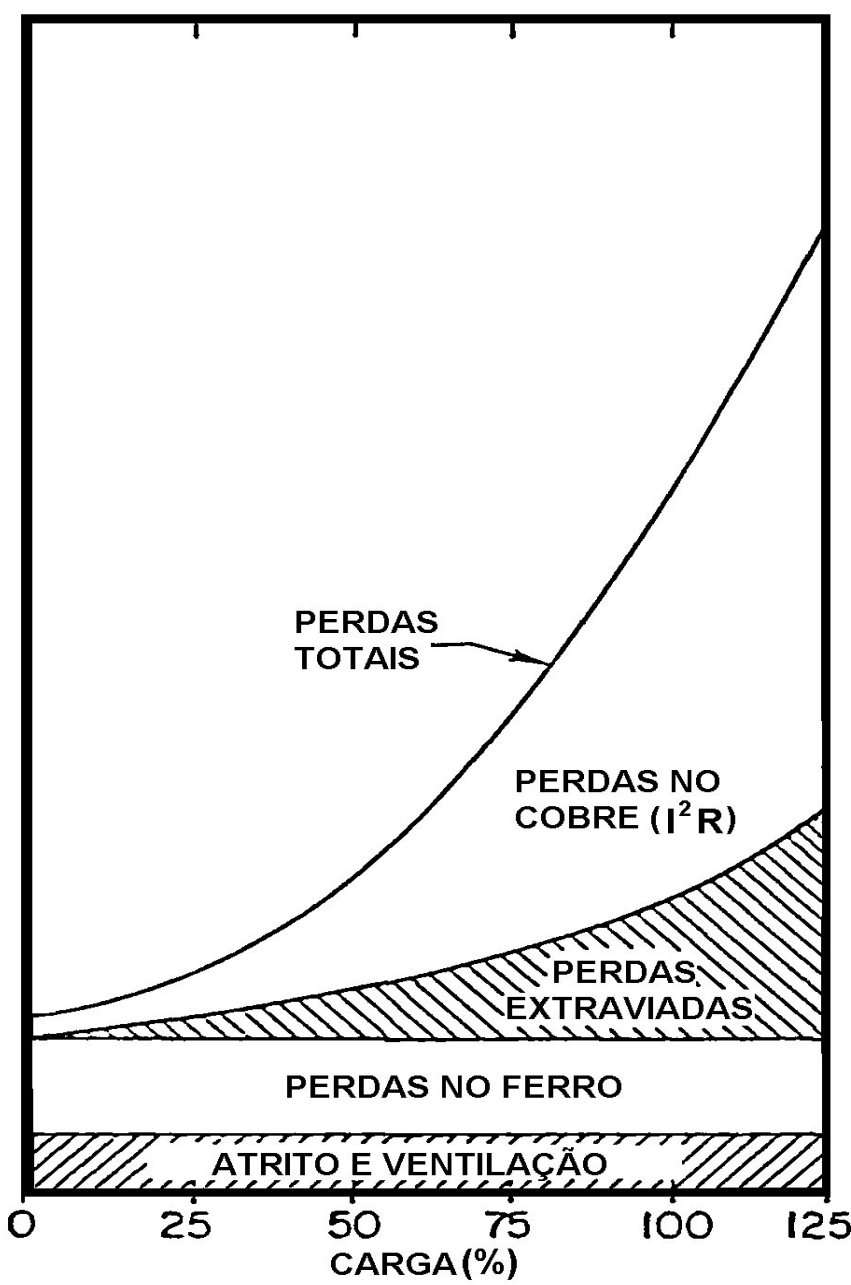

Figura 1 - Perdas nos equipamentos de força motriz

Os sistemas de força motriz não são apenas constituídos pelo motor eléctrico. Outros componentes do sistema, para além do motor, podem ser o Variador Electrónico de Velocidade, a Transmissão Mecânica e o Dispositivo de Uso Final. Na realidade, os equipamentos de força motriz podem integrar estes 4 módulos, como se ilustra na figura 2. Deve-se actuar ao nível de cada módulo, de forma a optimizar a eficiência do sistema global. Neste âmbito, merece particular atenção a utilização sempre que possível de Variadores Electrónicos de Velocidade (VEV).
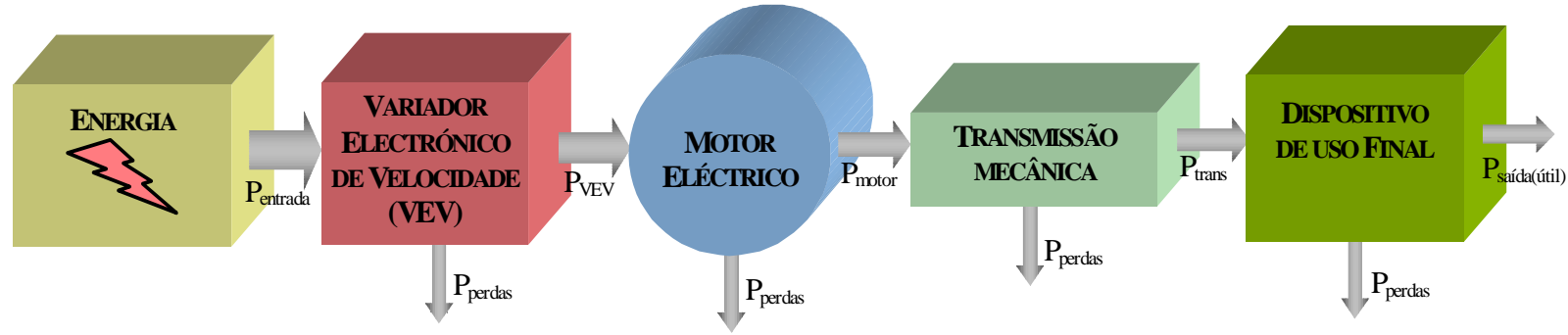

Figura 2 - Sistemas de Força Motriz 


\section{ARTIGO TÉCNICO}

\section{Classificação da Eficiência Energética}

Na Europa a classificação dos motores CA (Corrente Alternada) de baixa tensão foi estabelecida em 1998 com o acordo dos principais fabricantes de motores Europeus.

De uma forma resumida, o acordo estabelecido entre a Comissão Europeia (CE) e o Comité Europeu de Fabricantes de Máquinas Eléctricas e de equipamentos e sistemas de Electrónica de Potência (CEMEP) estabelecia que os motores de 1,1 a $90 \mathrm{~kW}$ de potência nominal, 50 ou $60 \mathrm{~Hz}$, com 2 e 4 pólos magnéticos, serão classificados de acordo com os valores dos respectivos rendimentos.

As classes de rendimento estabelecidas foram as seguintes:

- EFF1: Motores de elevado rendimento;

- EFF2: Motores de rendimento melhorado;

- EFF3: Motores de rendimento normal.

No acordo CE/CEMEP ficou ainda estabelecido que as vendas, na União Europeia, de motores EFF3 diminuiriam para metade até 2003. Este objectivo foi alcançado e a venda de motores EFF3 terminou pouco tempo depois.

Todos os fabricantes que assinaram este acordo estão autorizados a colocar a etiqueta de eficiência nos motores e em toda a documentação que os acompanhe, o que torna mais fácil a identificação da classe do motor.

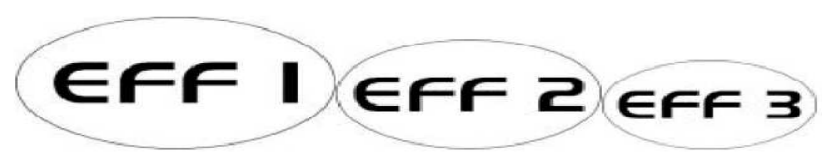

Figura 4 - Etiquetas de eficiência dos motores.

Com base no acordo voluntário anteriormente referido, foi também criada uma base de dados europeia EuroDEEM, que foi projectada pelo centro de pesquisa da Comissão Europeia (CE/JRC), com o objectivo de reunir num só suporte as informações mais importantes sobre os motores eléctricos disponíveis no mercado. Desta forma pretende-se que os utilizadores desta ferramenta possam fazer uma escolha bem fundamentada em termos técnicos e económicos dos seus sistemas (CARLOS GASPAR, 2004).

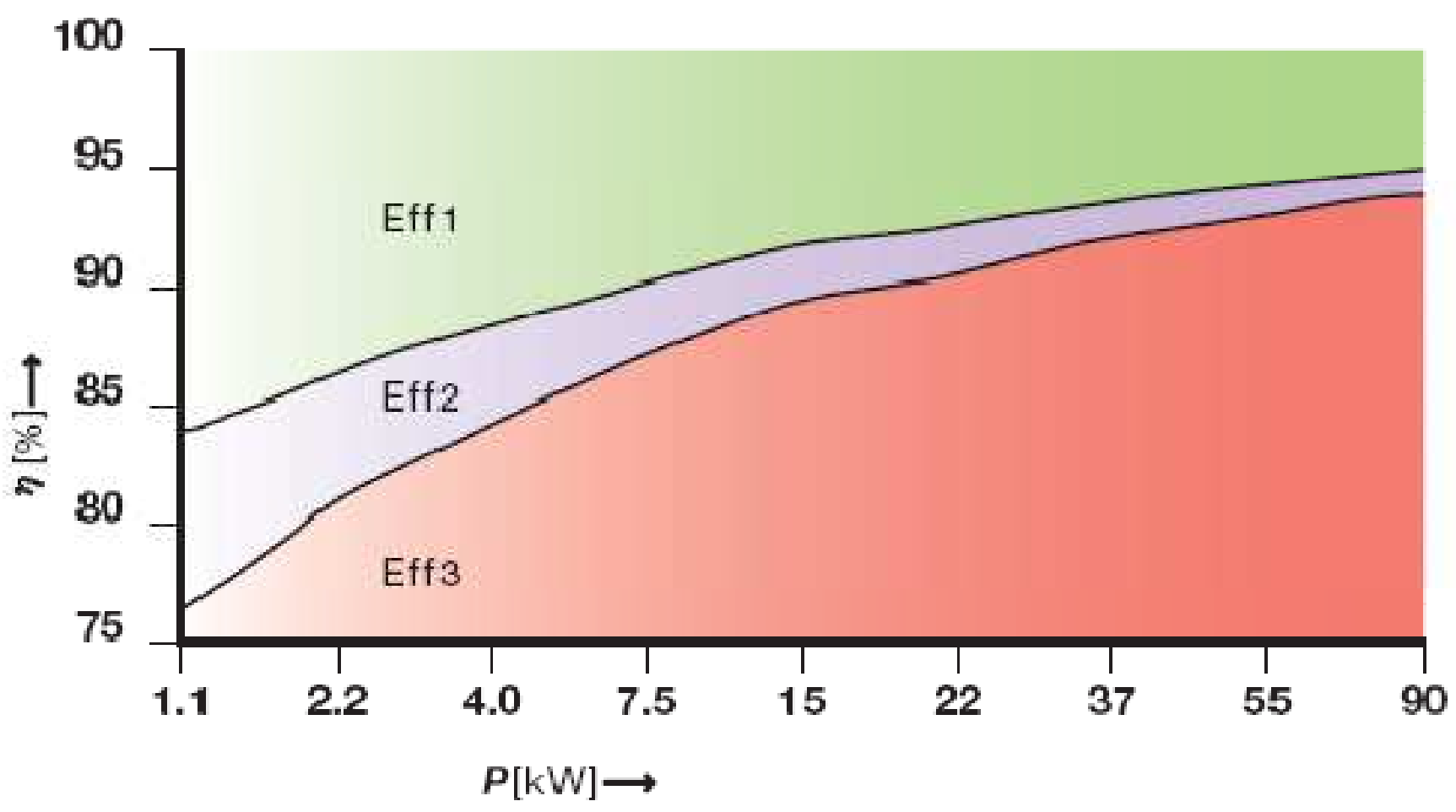

Figura 3 - Classes de eficiência de motores. [Rennie, 2000] 


\section{ARTIGO TÉCNICO}

A tabela I mostra o rendimento dos motores para cada uma das classes de eficiência estabelecidas.

\section{Características dos motores de elevado rendimento}

Actualmente, encontra-se já disponível no mercado os chamados motores de "perdas reduzidas", ou de "alto rendimento", mais caros que os motores clássicos, mas cuja utilização se revela rentável quando o seu tempo anual de utilização for suficientemente longo. Basicamente, o acréscimo de eficiência dos motores está associado a uma redução das suas perdas, que foi conseguida à custa, quer da utilização de materiais construtivos de melhor qualidade e com melhores acabamentos, quer por alteração das suas características dimensionais.
Os construtores aumentaram a massa de materiais activos (cobre e ferro) de forma a diminuir as induções, as densidades de corrente e, assim, reduzir as perdas no cobre e no ferro. Utilizam chapas magnéticas de perdas mais reduzidas, entalhes especiais em certos casos e reformularam a parte mecânica, com especial incidência sobre a ventilação, para reduzir a potência absorvida por esta e diminuir o nível de ruído. Daí resulta, para idêntica dimensão, um aumento de peso da ordem de 15\%, e de preço da ordem de 20 a 25\%. Contudo, a melhoria do rendimento, compreendida entre 2 e 4,5\%, e do $\cos \phi$, permite amortizar rapidamente este aumento de preço. As melhorias típicas que são efectuadas a nível construtivo da máquina podem ser visualizadas na figura seguinte e são resumidas na Tabela II.

Tabela I - Definição das diversas classes de eficiência

\begin{tabular}{|c|c|c|c|c|}
\hline kW & $\begin{array}{c}\text { EFF3 } \\
2 \text { e } 4 \text { pólos } \\
\eta_{n}(\%)\end{array}$ & $\begin{array}{c}\text { EFF2 } \\
2 \text { e } 4 \text { pólos } \\
\eta_{n}(\%)\end{array}$ & $\begin{array}{c}\text { EFF1 } \\
2 \text { pólos } \\
\eta_{n}(\%)\end{array}$ & $\begin{array}{c}\text { EFF1 } \\
4 \text { pólos } \\
\eta_{n}(\%)\end{array}$ \\
\hline 1,1 & $<76,2$ & $\geq 76,2$ & $\geq 82,2$ & $\geq 83,8$ \\
\hline 1,5 & $<78,5$ & $\geq 78,5$ & $\geq 84,1$ & $\geq 85,0$ \\
\hline 2,2 & $<81,0$ & $\geq 81,0$ & $\geq 85,6$ & $\geq 86,4$ \\
\hline 3 & $<82,6$ & $\geq 82,6$ & $\geq 86,7$ & $\geq 87,4$ \\
\hline 4 & $<84,2$ & $\geq 84,2$ & $\geq 87,6$ & $\geq 88,3$ \\
\hline 5,5 & $<85,7$ & $\geq 85,7$ & $\geq 88,6$ & $\geq 89,3$ \\
\hline 7,5 & $<87,0$ & $\geq 87,0$ & $\geq 89,5$ & $\geq 90,1$ \\
\hline 11 & $<88,4$ & $\geq 88,4$ & $\geq 90,5$ & $\geq 91,0$ \\
\hline 15 & $<89,4$ & $\geq 89,4$ & $\geq 91,3$ & $\geq 91,8$ \\
\hline 18,5 & $<90,0$ & $\geq 90,0$ & $\geq 91,8$ & $\geq 92,2$ \\
\hline 22 & $<90,5$ & $\geq 90,5$ & $\geq 92,2$ & $\geq 92,6$ \\
\hline 30 & $<91,4$ & $\geq 91,4$ & $\geq 92,9$ & $\geq 93,2$ \\
\hline 37 & $<92,0$ & $\geq 92,0$ & $\geq 93,3$ & $\geq 93,6$ \\
\hline 45 & $<92,5$ & $\geq 92,5$ & $\geq 93,7$ & $\geq 93,9$ \\
\hline 55 & $<93,0$ & $\geq 93,0$ & $\geq 94,0$ & $\geq 94,2$ \\
\hline 75 & $<93,6$ & $\geq 93,6$ & $\geq 94,6$ & $\geq 94,7$ \\
\hline 90 & $<93,9$ & $\geq 93,9$ & $\geq 95,0$ & $\geq 95,0$ \\
\hline
\end{tabular}

Tabela II - Resumo das alterações nos motores de elevado rendimento

\begin{tabular}{|l|l|}
\hline \multicolumn{1}{|c|}{ Alteração Efectuada } & \multicolumn{1}{c|}{ Efeito produzido } \\
\hline Tratamento térmico do rotor. & Redução da resistência. \\
\hline Uso de ferro laminado por camada. & Redução das perdas no ferro. \\
\hline Melhoria do circuito magnético. & Redução das perdas no ferro. \\
\hline Redução das bobines do circuito indutor. & Redução das perdas por efeito de Joule. \\
\hline Melhor qualidade dos rolamentos. & Redução das perdas mecânicas. \\
\hline Maior quantidade de cobre. & Diminuição de perdas e do calor gerado. \\
\hline Redução do entre-ferro. & Diminuição das perdas parasitas. \\
\hline Rotor mais largo. & Reactância de fugas menor. \\
\hline Sistema de ventilação melhorado. & Diminuição de ruídos e da temperatura. \\
\hline
\end{tabular}


Apesar de este tipo de motores possuir uma eficiência melhorada, quando inseridos num sistema, a eficiência total do mesmo sistema depende de todos os outros componentes que o compõem. Por este motivo, não se deve apenas investir na compra de um motor de elevada eficiência, quando existirem problemas de eficiência nos outros componentes do sistema.

\section{Estudo económico, em motores de elevado rendimento}

Como foi referido anteriormente, a opção por motores de elevado rendimento acarreta custos de investimentos sempre superiores ao investimento em motores standard. Por esse motivo só se torna economicamente vantajosa a aposta neste tipo de motores quando existe a necessidade de substituição de um motor ou quando se está a dimensionar uma nova instalação. Quase nunca a substituição de um motor standard, a funcionar correctamente, por um motor de elevado rendimento se torna economicamente vantajosa. Essa hipótese poderá ser considerada se o motor tiver um elevado número de horas de funcionamento anual.

A equação seguinte permite calcular a poupança que se obtém com um motor de elevado rendimento em comparação com um motor standard.

Poupança $=\left(\frac{1}{\eta_{S T D}}-\frac{1}{\eta_{E E}}\right) \times P_{N} \times N \times € / k W h$

em que,

$\eta_{E E} \quad$ representa o rendimento do motor standard

$\eta_{\text {STD }}$ representa o rendimento do motor de elevada eficiência

$P_{N} \quad$ representa a potência nominal do motor

$N \quad$ indica o número de horas de funcionamento anual

$€ / k W h$ traduz o preço da energia eléctrica.

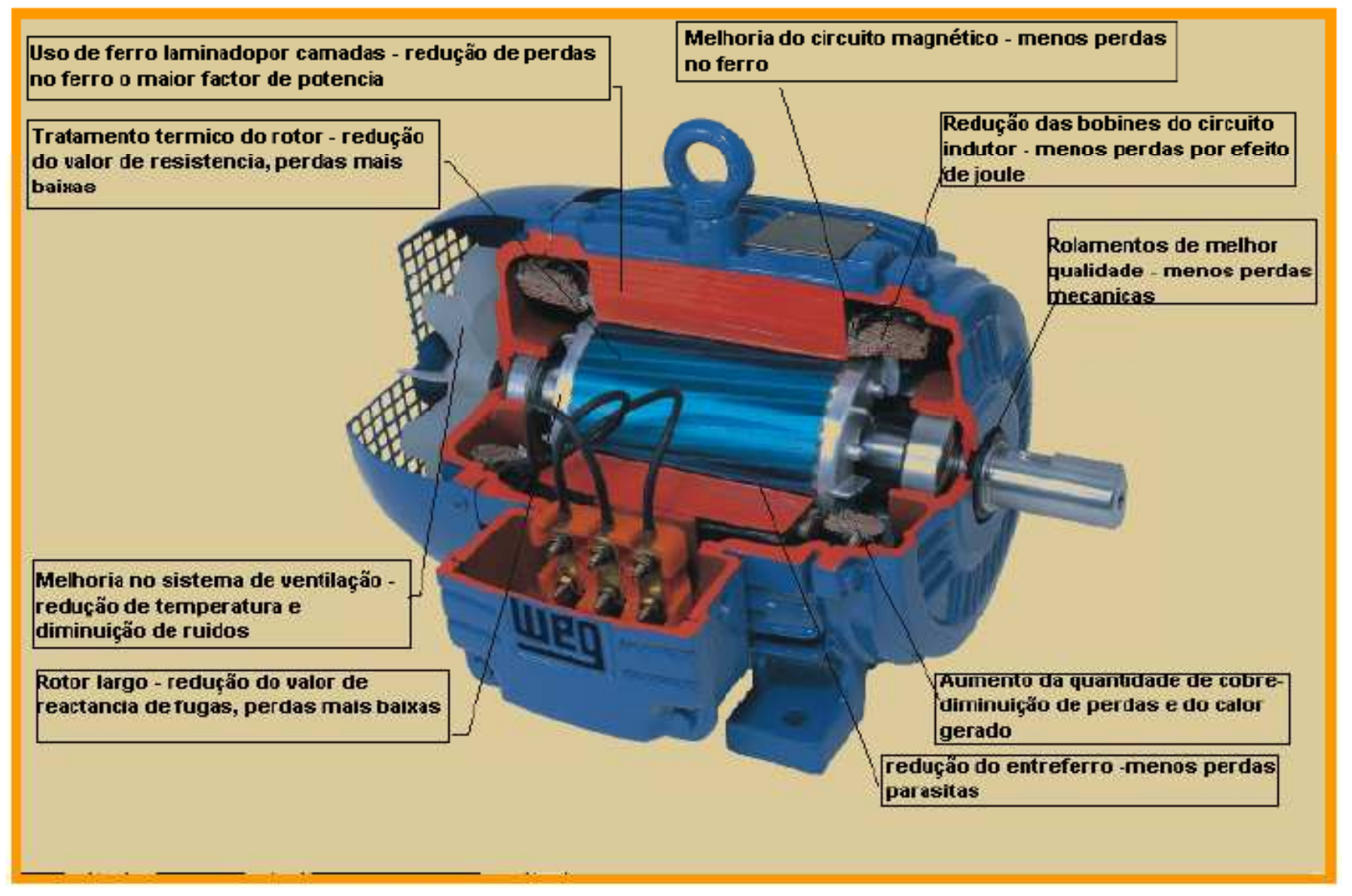

Figura 5 - Alterações nos motores de elevado rendimento [WEG] 


\section{ARTIGO TÉCNICO}

O acréscimo de custos dos motores de alto rendimento é recuperado através da economia de energia eléctrica que proporcionam. $\mathrm{O}$ tempo de recuperação $\mathrm{N}$ do investimento suplementar devido à instalação de motores de alto rendimento, pode ser calculado através da seguinte expressão:

$$
N=\frac{\Delta \mathrm{I}}{\Delta \mathrm{P} \cdot \mathrm{K} \cdot t}
$$

em que,

$$
\begin{array}{ll}
\Delta \mathrm{I} & \text { diferença de custos } \\
\Delta \mathrm{P} & \text { variação das perdas entre os dois motores } \\
\mathrm{K} & \text { preço do } \mathrm{kWh} \\
\mathrm{t} & \text { tempo de utilização (horas) }
\end{array}
$$

Se por exemplo considerarmos um motor de $30 \mathrm{~kW}$ a funcionar à plena carga durante 4000 horas anuais. Considerando um custo médio para a energia de 0,09€/kWh e que o rendimento dos motores EFF1 e EFF3 é respectivamente $93,2 \%$ e 91,4\%, então a poupança anual de energia é de cerca de $228,2 €$.

Considerando agora que a diferença de preço entre os dois motores é de $450 €$, então tempo de recuperação do capital devido à instalação do motor de elevado rendimento é de aproximadamente 2 anos.
Apesar de este ser apenas um exemplo e que usa pressupostos previamente estabelecidos, os valores encontrados são da mesma ordem de grandeza dos valores que se podem atingir na realidade. Para qualquer investimento em motores eléctricos efectuado, pelo menos, para 10 anos, os modelos de perdas reduzidas são fortemente competitivos.

6. Controlo de velocidade dos equipamentos de força motriz

Uma grande parte das aplicações em que se utiliza força motriz beneficiaria, em termos de consumo de electricidade e desempenho global, se a velocidade do motor se ajustasse às necessidades do processo. As aplicações com carga variável ou parcial representam cerca de $60 \%$ das aplicações de força motriz na indústria, e $80 \%$ no sector terciário. Assim, adaptar a velocidade do motor à carga conduz em geral a uma poupança substancial de energia. Os sistemas mais eficientes e mais utilizados no controlo e regulação de velocidade dos equipamentos de força motriz são os Variadores Electrónicos de Velocidade (VEV).

Os VEVs convertem a tensão alternada da rede de $50 \mathrm{~Hz}$ numa tensão contínua e em seguida numa tensão com frequência variável sob controlo externo do utilizador que pode ir de 0 a $150 \mathrm{~Hz}$ consoante o tipo de aplicações. $\mathrm{Na}$ figura 6 apresenta-se a estrutura de blocos de um VEV para um motor assíncrono de indução trifásico.

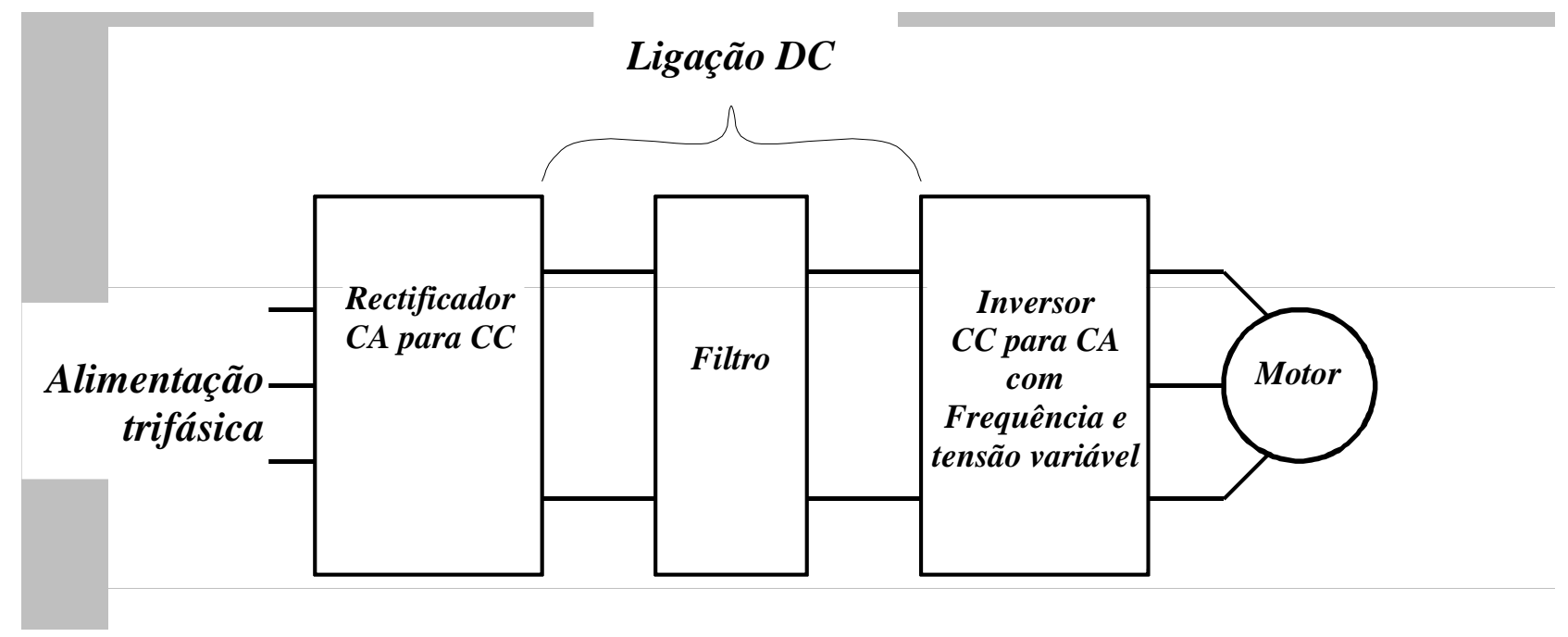

Figura 6- Diagrama de blocos de um Variador Electrónico de Velocidade 
As principais vantagens inerentes à utilização de um VEV são as seguintes:

○ Elevado rendimento (96 a 98\%) e elevada fiabilidade

- Elevado factor de potência

- Adaptação do motor à carga, em binário e velocidade

- Arranques suaves (poupança de energia) e frenagem controlada

- Protecção do motor contra curto-circuitos, sobrecargas, sobretensões, falta de fase, etc. Vantagem técnica e económica

- Poupança substancial de energia e tempo de retorno do investimento reduzido, especialmente em aplicações de controlo da caudais de bombas, ventiladores e compressores centrífugos

Menor desgaste de componentes e equipamentos mecânicos.

\section{Transmissão Mecânica nos Equipamentos de Força Motriz}

Tipicamente são usados 3 tipos de transmissão mecânica:

- Acoplamentos directos no veio;

○ Engrenagens;

○ Correias.
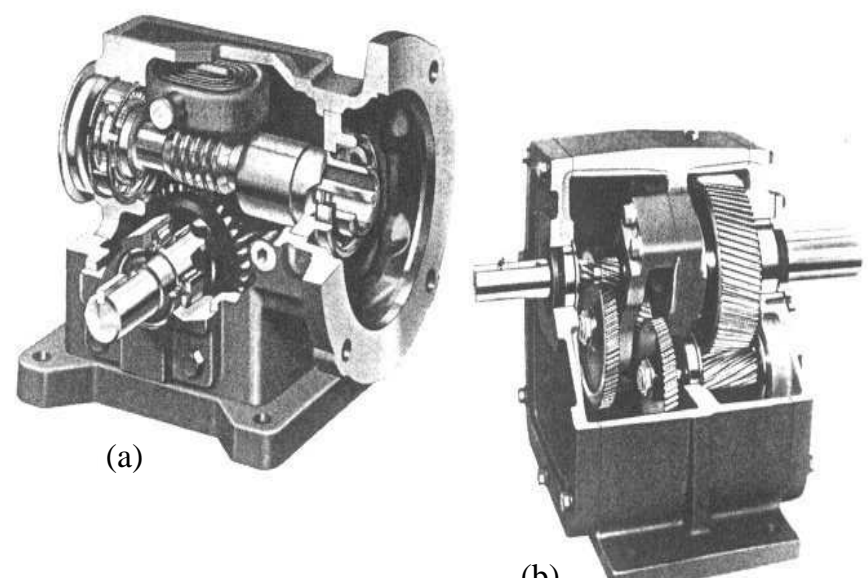

(b)

Os acoplamentos directos no veio são o tipo de transmissão mais utilizado (cerca de $50 \%$ das aplicações).

\section{Acoplamentos directos:}

Os acoplamentos directos, se forem alinhados com precisão, possuem um rendimento muito elevado (99\%).

\section{Engrenagens:}

As engrenagens simples ou redutoras, são tipicamente utilizados em cargas que requerem velocidades baixas (abaixo de 1200 rpm) e binário muito elevado (que utilizando correias poderia resultar em escorregamento). Existem vários tipos de engrenagens: helicoidais, de dentes direitos, cónicas e com sem-fim.

\section{Correntes:}

Tal como as correias síncronas, as correntes não têm deslizamento. Normalmente são usadas em aplicações onde é requerido uma velocidade reduzida e binário elevado, suportam ambientes com temperaturas elevadas e cargas de choque e têm um tempo de vida elevado se forem apropriadamente lubrificadas. O seu rendimento ascende aos $98 \%$ se forem sujeitas a uma manutenção periódica.

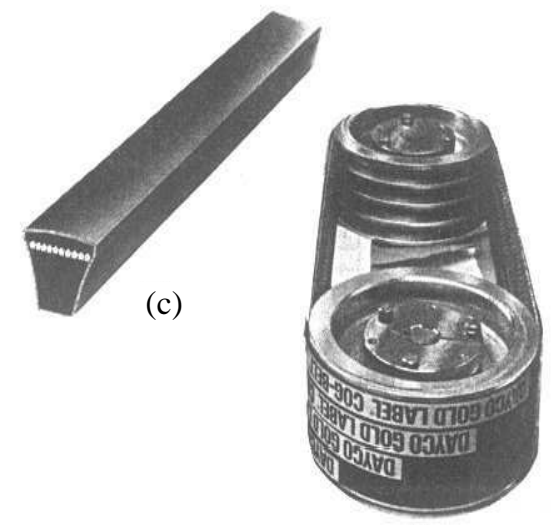

(d)

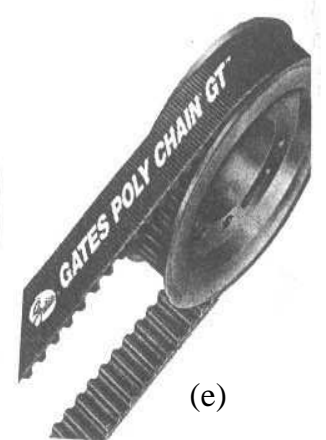

Figura 7 - Transmissão Mecânica em equipamentos de força motriz. 


\section{ARTIGO TÉCNICO}

\section{Correias:}

Estas permitem mais flexibilidade no posicionamento do motor em relação à carga, e usando polias de diferentes tamanhos permitem reduzir/aumentar a velocidade. Existem vários tipos de correias: (a) Correias em V, (b) Correias com dentes, (c) correias síncronas, (d) correias lisas.

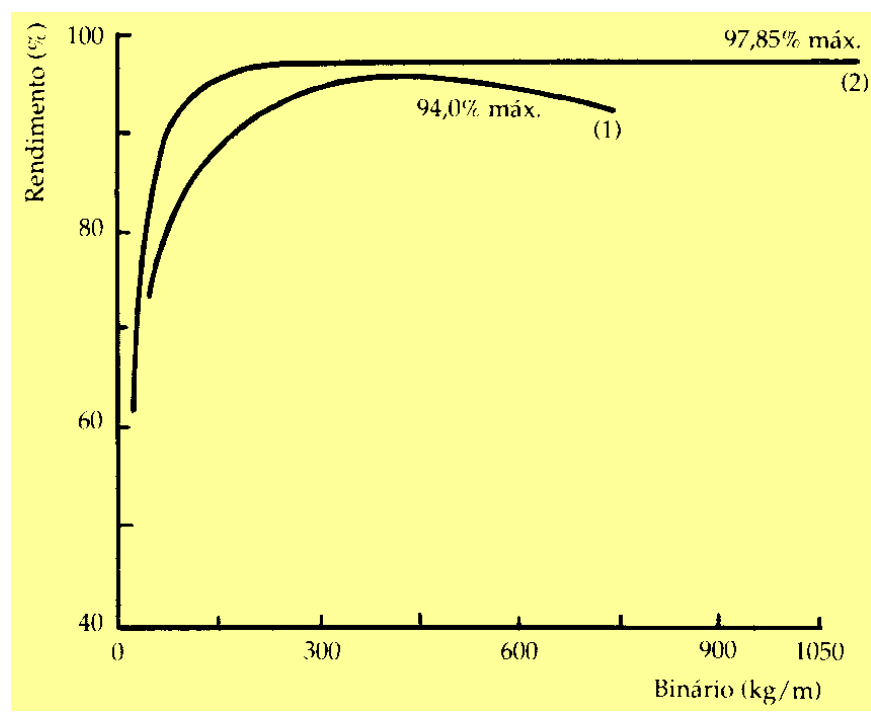

Figura 8 - Tipos de correias: 1-correias trapezoidais 2correias síncronas

\section{Considerações Finais}

A produção de energia mecânica, através da utilização de motores eléctricos, absorve cerca de metade da energia eléctrica consumida no nosso País, da qual apenas metade é energia útil. Este sector é, pois, um daqueles em que é preciso tentar fazer economias, prioritariamente. Como se apresentou neste artigo, os pontos fundamentais em que se deve intervir são os seguintes:

- Dimensionar correctamente os equipamentos de força motriz, fazendo os motores funcionar com cargas da ordem dos 70 a $80 \%$.

- Adaptar a velocidade do motor às necessidades do processo, utilizando sempre que necessário dispositivos electrónicos de variação de velocidade.

- Utilizar os novos motores de "alto rendimento", que já provaram a sua competitividade apesar do seu custo superior, devendo-se ponderar sempre que necessário a sua utilização. Como se demonstrou neste artigo, os ganhos de eficiência com os motores de alto rendimento, vão desde $1 \%$ a $5 \%$, o que se pode traduzir por importantes reduções do seu consumo eléctrico; contudo, pela sua concepção, são naturalmente motores que exigem um investimento inicial superior ao dos motores standard (cerca de 25\% a 30\%). Face a este acréscimo de custos de investimento, é conveniente efectuar-se uma análise económica prévia; pode no entanto, considerar-se tipicamente que, em situações de aquisição de novos motores, a sua utilização é normalmente justificada, sendo o sobrecusto amortizado em 1 a 2 anos, para um período de laboração da ordem das 4000 h/ano, e em cerca de 3 anos, para 2000 h/ano de funcionamento.

Atender às necessidades de manutenção dos motores, que são essencialmente a limpeza da carcaça, a fim de reduzir a temperatura, e nalguns casos a lubrificação dos rolamentos.

\section{Fontes de Informação Relevantes}

BELEZA CARVALHO, J. A., MESQUitA BRANDÃO, Eficiência Energética em Equipamentos de Força Motriz. Jornadas Luso-Brasileiras de Ensino e Tecnologia em Engenharia. ISEP, Porto, Fevereiro de 2009.

BELEZA CARVALHO, J. A., MESQUitA BRANDÃO, R. F., Efficient Use of Electrical Energy in Industrial Installations. 4TH European Congress Economics and Management of Energy in Industry. Porto, Novembro de 2007.

CARLOS GASPAR, Eficiência Energética na IndustriaADENE, Cursos de Utilização Racional de Energia, 2004.

GARCIA, A. G. Impacto da Lei de Eficiência Energética para Motores Eléctricos no Potencial de Conservação de Energia na Indústria. 2003. Dissertação (Mestrado em Planeamento Energético) - Universidade Federal do Rio de Janeiro-COPPE, Rio de Janeiro.

IAN RENNIE, Improving Motor Efficiency for a Better Environment. ABB Review, 1/2000.

WEG, Catálogo de Motores Eléctricos, disponível em http://www.weg.com.br/. 